\title{
Study of Technology for Ultrafine-Grained Materials for Usage as Materials in Nuclear Power
}

\author{
Abdrakhman Naizabekov \\ Rudny Industrial Institute, Kazakhstan \\ Alexandr Arbuz \\ Nazarbayev University, Kazakhstan \\ Sergey Lezhnev \\ Rudny Industrial Institute, Kazakhstan \\ Evgeniy Panin \\ Karaganda State Industrial University, Kazakhstan \\ Marcin Knapinski \\ Czestochowa University of Technology, Poland
}

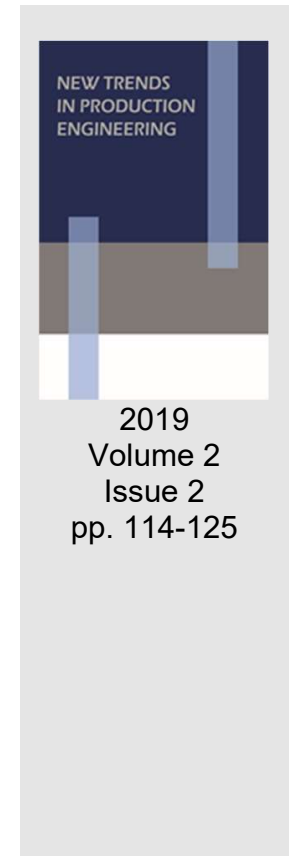

Date of submission to the Editor: 09/2019

Date of acceptance by the Editor: 11/2019

\section{INTRODUCTION}

The rapidly growing long-term demand for energy and the increasing importance of environmental problems postulate the leading role of nuclear and future thermonuclear energy among other sources to meet the future energy needs of mankind (Zinkle \& Busby, 2009).

Alternative energy sources (wind and solar) despite the conditional inexhaustibility and eco-concept, have a number of common problems with low efficiency, high cost and low return on investment, the requirements of the climate and the area, at that time, as the energy consumption steadily increases and requires a more effective solutions.

Nuclear power does not have the above disadvantages, but it is associated with great environmental risks. In many ways, the problem of accidents, leaks, and increasing the service life of elements of nuclear power plants is solved through the use of improved materials (Mansur et al., 2004, Zinkle \& Was, 2013, Murty \& Charitl, 2008, Yvon \& Carr, 2009). Similarly, the high properties of materials will be critical to the future success of advanced thermonuclear reactors, which will expose the metal structure of their design to unprecedented high-energy neutron fluxes along with intense thermomechanical stresses (Kalinin et al., 2000, Bloom, 1998).

Thus, based on the operating conditions of nuclear power plant structures, the requirements for materials can be the following: high corrosion resistance; high temperature resistance; creep resistance; fracture toughness; stability of the structure and properties under irradiation. This makes it relevant to search for materials capable of withstanding long-term (including dynamic) loads in 
conditions of high temperatures, aggressive environment and gradual structural degradation under the influence of radiation. The last factor is key, since materials with other requirements are successfully used in other industries not related to contact with radiation - for example, chemical technology, heat power, metallurgy, engine parts.

Structural materials under the influence of irradiation experience structural transformations that have a negative impact primarily on mechanical properties and corrosion resistance. Corrosion-resistant steels and aluminum alloys exhibit the greatest resistance to radiation (Ge et al., 2019). However, the corrosion rate of aluminum - based alloys in the water environment under irradiation increases by 2-3 times, which is significantly less than austenitic chromiumnickel steels, which, nevertheless, in wet steam are also subject to intercrystalline corrosion and corrosion cracking. Therefore, the use of steel, and primarily austenitic stainless steel, is the most reasonable.

One of the ways to improve both mechanical and operational properties and radiation resistance of metal products is the use of metal materials with ultrafine-grained (UFG) structure for their manufacture. Such materials due to the small grain size contain a large number of grain boundaries in the structure, which affect their mechanical and physical properties. At the same time, grain boundaries should be predominantly small-angle, and the grains themselves should be equiaxed, with sizes less than 1 micron. Such structures provide a combination of a high level of strength characteristics with high plasticity, which fundamentally distinguishes such materials from conventional ones. Also, numerous grain boundaries serve as runoff surfaces for radiation defects, preserving the structure, which causes their increased radiation resistance (Maksimkin et al., 2015).

From all methods of obtaining sub-ultra-fine-grained materials the most promising is the severe plastic deformation, due to the possibility of obtaining isotropic products of a larger volume, without internal discontinuities. Thus, bringing the metal microstructure into an ultra-fine-grained state opens up great prospects in the field of material engineering (Valiev et al., 2000, Koch et al., 2007).

Most of the methods of obtaining UFG materials by severe plastic deformation do not allow to provide a sufficient number of UFG materials with sufficient dimensions for commercial products. For example, the most frequently used and studied method as equal-channel angular pressing, has critical restrictions on the length of the resulting workpiece, which greatly complicates its industrial application (Koch et al., 2007).

To solve the problem of obtaining long-length blanks with UFG structure is possible by using radial-shear rolling (RSP) (Sheremetyev et al., 2019, Dobatkin et al., 2019). The difference between this method of rolling and conventional screw rolling is that a solid round bar is rolled according to a three-roll scheme with increased feed angles of the rolls, which contributes to the intensification of shear deformation and non-monotonicity of the metal flow under the predominance of the hydrostatic compression scheme (Valiev et al., 2000). 
Such conditions are favorable for the UFG structure formation, especially at low deformation temperatures. Therefore, this deformation method has a great potential for obtaining long metal products with UFG structure, because unlike other methods, it is as simple, effective and technological as possible.

\section{COMPUTER SIMULATION}

The aim of this work was to study the process of radial-shear rolling of austenitic stainless steel and to identify its impact on the microstructure evolution and change in mechanical properties. At the first stage of these studies, computer modelling was carried out in the Simufact Forming software package with the Matilda material base, which allows modelling the microstructure evolution.

To create a model of radial-shear rolling, it was decided to use the parameters of the existing SVP-08 mill installed at Rudny industrial institute. The initial billet with a diameter of $30 \mathrm{~mm}$ and a length of $200 \mathrm{~mm}$ was rolled on the mill with a compression of $3 \mathrm{~mm}$. The billet material is stainless austenitic steel AISI-321 $(0.08 \% \mathrm{C}, 17-19 \% \mathrm{Cr} ; 9-11 \% \mathrm{Ni} ; 2 \% \mathrm{Mn} ; 0.8 \% \mathrm{Si} ; 0.5-0.7 \% \mathrm{Ti})$, since it is the main structural material of nuclear power. In particular, it is used for the manufacture of fuel rod tubes of the most advanced fast neutron reactors. Also, this brand is used for the production of equipment operating in environments of high temperature and aggressiveness (heat exchangers, pipes, parts of furnace and reactor valves, spark plug electrodes). As for the selected grade of steel the initial temperature of recrystallization or diffusion annealing is equal to $1020^{\circ} \mathrm{C}$ (Ghazani \& Eghbali, 2018), the heating temperature of the steel was equal to $1000^{\circ} \mathrm{C}$ (base model), as the maximum possible for elimination of the recrystallization process, $900^{\circ} \mathrm{C}$ and $800^{\circ} \mathrm{C}$, as low as possible for the implementation of the rolling at mill SVP-08; the rolling speed was set to $50 \mathrm{rpm}$ as the nominal value at mill SVP-08. The coefficient of friction at the contact of the workpiece and the rolls was taken to be 0.5 , as the recommended value for hot rolling. The resulting model is shown in Figure 1.

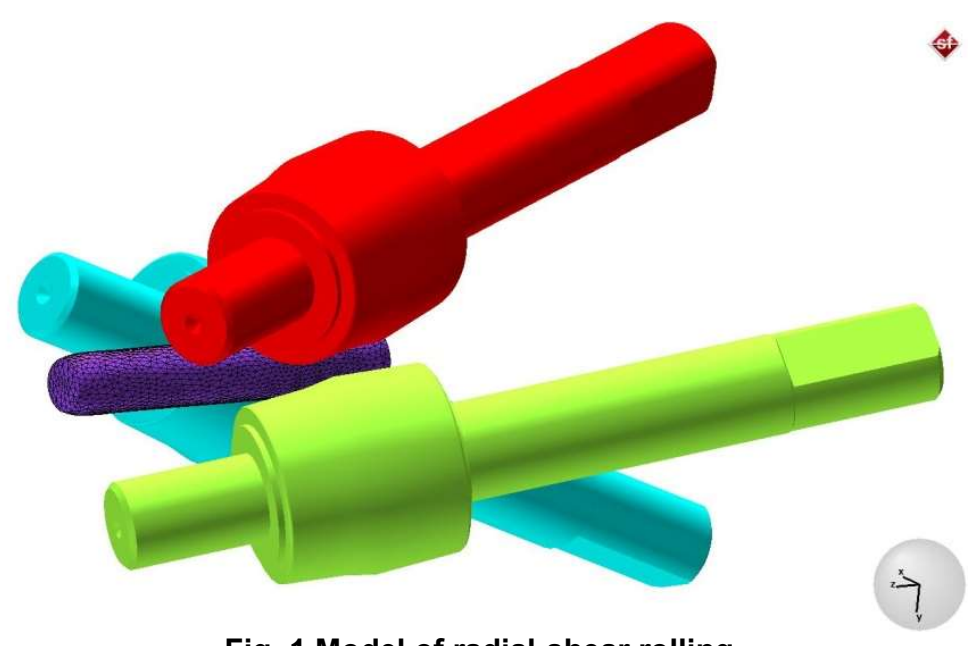

Fig. 1 Model of radial-shear rolling

In the study of any metal forming process, the main position before the laboratory experiment is the study of the stress-strain state (SSS) (ASM 
International, 2002). This makes it possible to identify the distribution of stresses and strains in the deformable workpiece, as well as to determine their critical values, which will make it possible to check the working tool for strength.

Complex consideration of the stress-strain state in the radial-shear rolling showed that in the implementation of this process in the workpiece there are favorable conditions for intensive study of the initial structure of the metal - in the entire cross section is dominated by compressive stresses, combined with a sufficiently high level of shear deformation due to the twisting of the workpiece. After the study of SSS was also investigated by computer simulation, and the effect of radial-shear rolling on the microstructure evolution of steel AISI-321.

During deformation there are two kinds of recrystallisation (static and dynamic), which have influence on initial grain size. Calculation of dynamic recrystallisation is the part of model, which refers to the processes in the forming zone. It starts when the effective log. strain $\varepsilon$ exceeds the critical strain $\varepsilon$ k. Main data in this model is Zener-Hollomon parameter (Rajputa et al., 2016):

$$
Z=\dot{\varepsilon} \cdot \exp \left(\frac{Q}{R T}\right)
$$

where:

$\dot{\varepsilon}$ - strain rate, $\mathrm{s}^{-1}$

$\mathrm{Q}$ - activation energy for forming, $\mathrm{J} / \mathrm{mol}$;

$\mathrm{R}$ - gas constant equal $8.3144 \mathrm{~J} /(\mathrm{mol} \cdot \mathrm{K})$;

$\mathrm{T}$ - forming temperature, $\mathrm{K}$.

Critical strain for beginning of dynamic recrystallisation:

$$
\varepsilon_{\mathrm{k}}=\left[\mathrm{a} 1 \cdot \mathrm{D}_{0} \mathrm{a}^{2} \cdot \mathrm{Z}^{\mathrm{a} 3}+\mathrm{a} 4\right] \cdot \mathrm{a} 5
$$

where:

a1-a5 - model coefficients;

$\mathrm{D}_{0}$ - initial gain size, $\mu \mathrm{m}$;

Z - Zener-Hollomon parameter.

Log. strain to $50 \%$ of dyn. recrystallisation:

where:

$$
\varepsilon_{50}=\left[\mathrm{c} 1 \cdot \mathrm{D} 0^{\mathrm{c} 2} \cdot \exp (\mathrm{c} 3 / \mathrm{T}) \cdot \dot{\varepsilon}^{\mathrm{c} 4}\right]+\mathrm{c} 5
$$

c1-c5 - model coefficients.

Dynamic recrystallised part:

$$
\mathrm{X}_{\text {Dyn }}=1-\exp \left[\mathrm{f1} \cdot\left(\left(\varepsilon-\varepsilon_{\mathrm{k}}\right) / \varepsilon_{50}\right)^{\mathrm{f} 2}\right)
$$

where:

$\mathrm{f} 1, \mathrm{f} 2$ - model coefficients.

Dynamic recrystallised grain size, $\mu \mathrm{m}$ :

$$
D_{\text {Dyn }}=\mathrm{d} 1 \cdot \mathrm{Z}^{\mathrm{d} 2}
$$

where:

d1, d2 - model coefficients.

Calculation of static recrystallisation is the part of model, when the workpiece segment leave the forming zone.This is valid until the recrystallisation process is interrupted to a new forming or a phase transition. It starts when the effective 
log. strain $\varepsilon$ exceeds the critical strain $\varepsilon k$ and it ends when the temperature is below the lower application range boundary.

Mean log. strain after starting of dynamic recrystallisation:

$$
\varepsilon_{\mathrm{m}}=\mathrm{p} 2 \cdot\left(\varepsilon_{\mathrm{k}}+\varepsilon_{50} \cdot\left\{1-\exp \left[-\left(\varepsilon-\varepsilon_{\mathrm{k}}\right) / \varepsilon_{50}\right]\right\}\right)
$$

where:

p2 - coefficent for model adaptation.

Time to $50 \%$ of static recrystallisation, s:

$$
\mathrm{t}_{50}=g 1 \cdot \varepsilon^{g 2} \cdot D_{0}^{g 3} \cdot \exp \left(\frac{g 4}{T}\right) \cdot \dot{\varepsilon}^{g 5}
$$

where:

g1-g5 - model coefficients.

Time for begin and end of static recrystallisation, s:

$$
\begin{aligned}
& t_{05}=b 1 \cdot t_{50} \\
& t_{95}=b 2 \cdot t_{50}
\end{aligned}
$$

where:

b1, b2 - model coefficients.

Temperature corrected pause time, s:

$$
\mathrm{t}_{\mathrm{P}_{-} \text {kor }}=\sum\left\{d_{T i} \cdot \exp \left[-\left(\frac{Q_{S T}}{1000 \cdot R \cdot T}\right)\right]\right\}
$$

where:

$\mathrm{d}_{\mathrm{Ti}}$ - length of time increment $\mathrm{i}, \mathrm{s}$;

Qst - activation energy for static recrystallisation, $\mathrm{J} / \mathrm{mol}$.

Static recrystallized part:

where:

$$
X_{\text {stat }}=1-\exp \left[\mathrm{m} 2 \cdot\left(\mathrm{t}_{\mathrm{f}} \text { kor } / \mathrm{t}_{50}\right)^{\mathrm{m} 1}\right]
$$

$\mathrm{m} 1, \mathrm{~m} 2$ - model coefficients.

Static recrystallized grain size, $\mu \mathrm{m}$ :

$$
D_{\text {stat }}=\left[s 1 \cdot \varepsilon^{s 2} \cdot D_{0} s 3 \cdot Z^{s 4}\right]+s 5
$$

where:

s1-s5 - model coefficients.

Mean grain size at the end of recrystallisation:

$$
D=X_{D y n} D_{D y n}+\left(1-X_{D y n}\right) X_{\text {Stat }} D_{\text {Stat }}+\left[1-X_{D y n}-\left(1-X_{D y n}\right) X_{\text {Stat }}\right] D_{0}
$$

In large forming pauses the process of grain growth starts directly after the end of dynamic and static recrystallisation when $\left(X_{\text {Dyn }}+X_{\text {stat }}\right)>95 \%$ and (tP_kor $\left.-t_{95}\right)$ $>0$ the new mean grain size $\mathrm{mKG}$ in $\mu \mathrm{m}$ is calculated according to:

$$
m K G^{w 1}-D^{w 1}=w 2 \cdot\left(t_{P} \text { kor }-t_{95}\right) \cdot \exp [-Q /(R T)]
$$

where:

w1, w2 - model coefficients.

The coefficients in equations (2-13) are individual for different materials and deformation modes. All of them are considered in detail in works (Lenard et al., 2005, Lenard, 2013), where a large number of values of these coefficients for 
different grades of steels and alloys are presented, depending on the types of deformation and thermal treatments.

Analysis of the microstructure evolution showed that reducing the heating temperature of the workpiece is a very effective method for intensifying the process of grain grinding. Despite the fact that in all three models considered the level of dynamic recrystallization remains constant (due to the constant level of compression), the share of static recrystallization with a decrease in the heating temperature is also reduced. This leads to a greater increase in the degree of grinding of the initial grain in the metal, especially in the surface area, as can be seen from the diagram, reflecting the average grain size for the three temperatures (Figure 2).

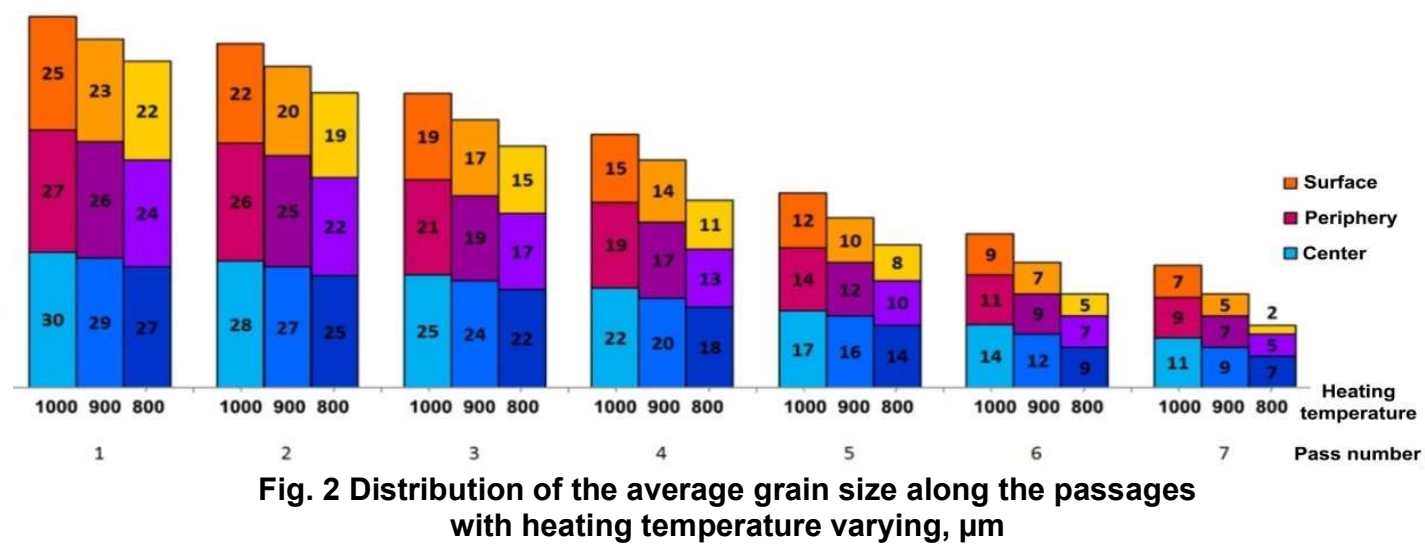

Analysis of the diagrams in Figure 2 shows that with a decrease in the initial temperature, the grinding of the initial grain size occurs more intensively in all three zones, but the largest grinding of grain is observed in the surface zone, where after 7 passes at a heating temperature of the workpiece $900^{\circ} \mathrm{C}$, The grain size of $5 \mu \mathrm{m}$ was fixed, which is 1.4 times less than the value in the base model, i.e. at a temperature of $1000^{\circ} \mathrm{C}$. In the case of heating the workpiece to $800^{\circ} \mathrm{C}$, the grain size of $2 \mu \mathrm{m}$ was fixed in the surface zone, which is 3.5 times less than the value in the base model. In the other two zones, there is also a significant grain grinding at lower temperatures. Thus, with a decrease in heating by $100^{\circ} \mathrm{C}$, the average grain size after 7 passes decreases by $22 \%$ in the axial zone, by $28 \%$ in the peripheral zone. When heating is reduced by $200^{\circ} \mathrm{C}$, the average grain size after 7 passes is reduced by $57 \%$ in the axial zone, by $80 \%$ in the peripheral zone.

\section{EXPERIMANTAL PART}

Using the data of finite element simulation obtained earlier in works (Nayzabekov et al., 2018, Lezhnev et al., 2018), it was decided to conduct a fullscale experiment for the conditions defined as optimal. Thus, the plan of the experiment included the rolling of rods with a $30 \mathrm{~mm}$ diameter on the radialshear rolling mill SVP-08 (Figure 3) to a $9 \mathrm{~mm}$ diameter in 7 passes with a compression $3 \mathrm{~mm}$ in each pass, at a temperature of $800^{\circ} \mathrm{C}$ with a standard speed of rolls rotation $50 \mathrm{rpm}$. 


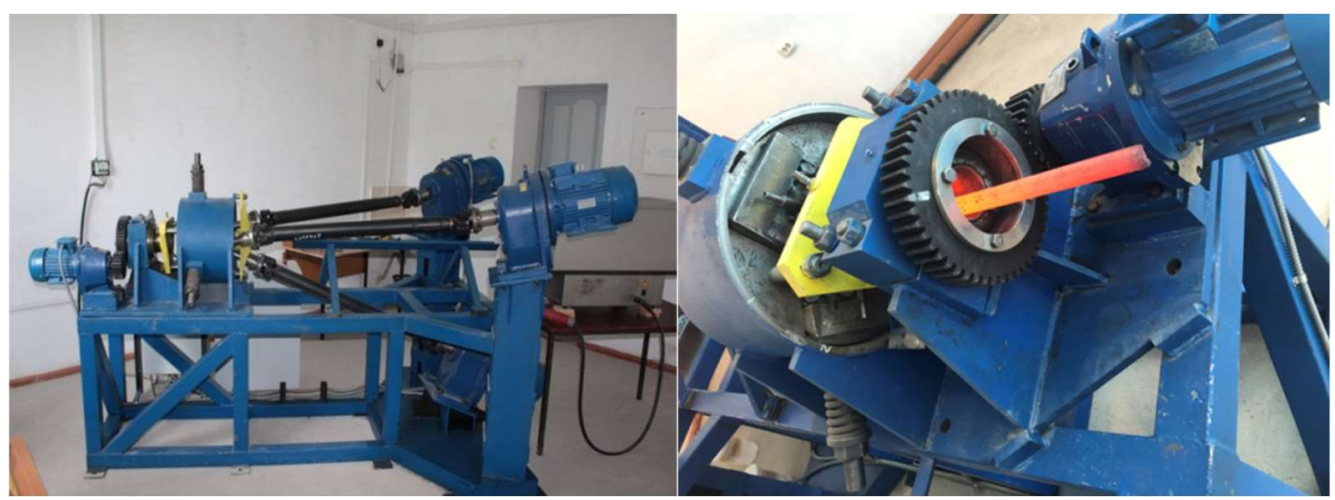

Fig. 3 Radial-shear rolling mill SVP-08 and rolling process on it

To eliminate the influence of reheating, it was decided to roll all bars with one heating the required number of passes, therefore, to study the evolution of the microstructure and mechanical properties, 7 samples were used, one sample for each final diameter. Two more samples were rolled to duplicate the results in each pass. The fourth and last passages were chosen as duplicates.

Each initial sample was a rod with a diameter of $30 \mathrm{~mm}$ and a length of $200 \mathrm{~mm}$. The sample material was austenitic stainless steel AISI-321 (0.08\% C; 17-19\% $\mathrm{Cr} ; 9-11 \% \mathrm{Ni} ; 2 \% \mathrm{Mn} ; 0.8 \% \mathrm{Si}$ 0.5-0.7\% Ti). After achieving the desired diameter, the intense cooling of the rod with water was produced. A similar temperature regime for the production of stainless steel structure UFG was used in work (Ge et al., 2019).

After rolling from each bar on a high-precision cutting machine Struers AccuTom- 5 along the bar were cut samples in the form of strips $30 \times 3 \times 0.3 \mathrm{~mm}$ for mechanical testing, as well as prepared micro-plates for studying the microstructure evolution. 3 strips from each point of the experiment (plus 3 strips from the duplicate samples for passes 4 and 7) were taken for the tensile test. Samples were also cut and prepared for mechanical testing and study of the microstructure of the starting material.

Mechanical properties were determined by tensile testing of flat specimens on the Instron-1195 test machine. For testing were taken from the strips, the central line of which is at a distance $1 / 2$ of the rod diameter that will allow to obtain the most objective results given the anticipated heterogeneity of the microstructure in the cross section of the rod. The test results for each point were averaged and presented as graphs in Figure 4.

It can be concluded from the graphs that the mechanical properties change monotonically depending on the number of passes. At the same time, the tensile strength increased almost 2 times to a value of $1073 \mathrm{MPa}$, and the elongation, which is one of the indicators of material plasticity, is reduced by 2 times, reaching $21 \%$, against the initial $40 \%$. The decrease of elongation in this case is within the norm for materials that have undergone such processing and is comparable with the known data, for example, when this material is deformed by the ECAP method (Rybalchenko et al., 2016). 

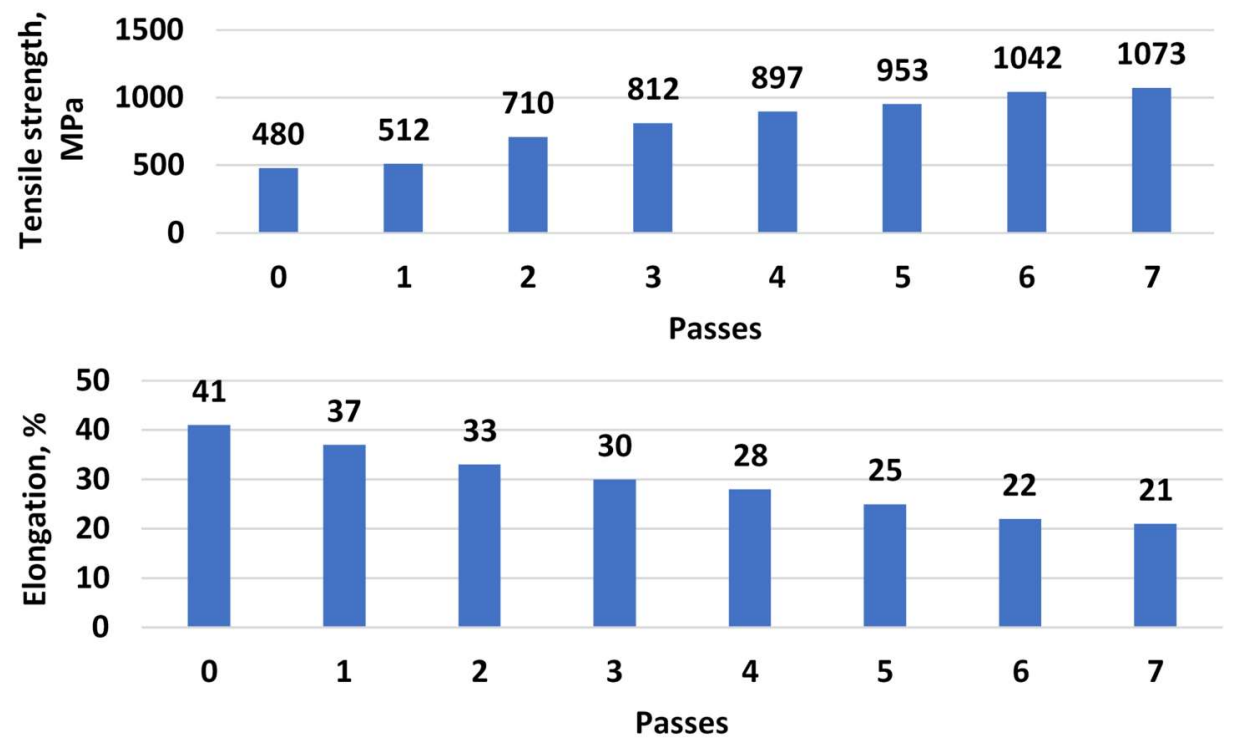

Fig. 4 Mechanical properties of austenitic stainless steel AISI-321 after radial-shear rolling by passes

Further, using the remaining halves of the rod a study of the microhardness was performed. The measurements were carried out on hardness testing machine HVS-1000B with a force of $9.87 \mathrm{~N}$ at shutter speeds of 15 seconds. For each sample, 7 measurements were done at a distance of at least 2.5 imprint sizes from the point of the previous measurement. The initial micro-hardness was 160 $\mathrm{HV}$. After radial-shear rolling, the microhardness level increased to 288-321 HV and generally increased by 2 times compared to the original. The results were averaged over the passages and presented as a graph in Figure 5a.

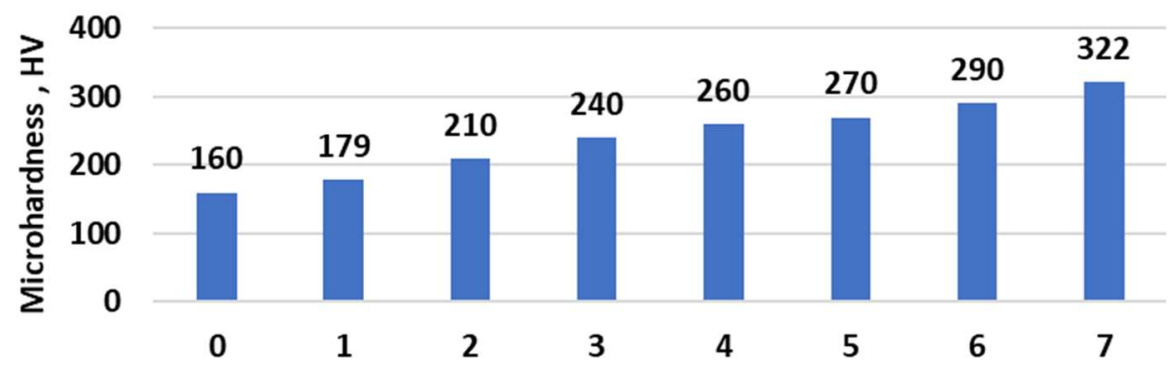

a)

Passes

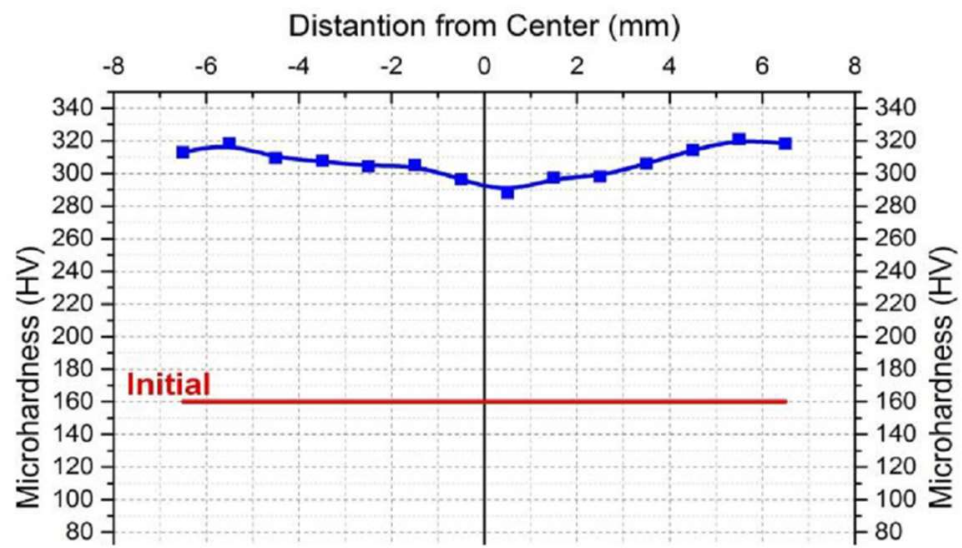

b)

Fig. 5 Microhardness HV of austenitic stainless steel AISI-321 after radial shear rolling $a$ - by passes; $b$ - in the cross section of rod after the final pass 
Taking into account the predicted heterogeneity of the microstructure at large deformations, it was decided to investigate the change in microhardness along the bar cross section for the last 7 th pass, since this sample will further serve for the preparation of samples for irradiation. In order to build the microhardness profile, measurements were carried out through each millimetre of the sample section 3 times at each point of the graph. The results for each point were averaged. The graph of change of microhardness on section is shown in Fig. $5 b$.

As expected, due to the structural heterogeneity over the cross section of the rod is observed a gradual decline of the microhardness in the axial zone of the rod by $10.2 \%$ (33 HV). Otherwise, the level of microhardness is high enough throughout the cross section without sharp dips.

Then the microstructure was studied using a transmission electron microscope (TEM). Samples were prepared by the electrolytic method in a solution $(600 \mathrm{ml}$ Methanol, $360 \mathrm{ml}$ Butylcellosolve, $60 \mathrm{ml}$ Perchloric Acid) and examined on transmission electron microscope JEM-2100 at an accelerating voltage of 200 $\mathrm{kV}$. The microstructure was investigated in the center and the periphery of the cross section of the rod. The average grain size was calculated by secant method (Bhadeshia, 2014) by the most characteristic fields for each sample. The calculation was carried out on samples cut from the peripheral zone, since the largest grinding and formation of the required equiaxed UFG structure occurs exactly there (Figure 6). This is also due to the fact that a fibrous texture with long elongated grains is formed in the axial zone on the last passes and therefore the determination of the average grain value is difficult and incorrect.

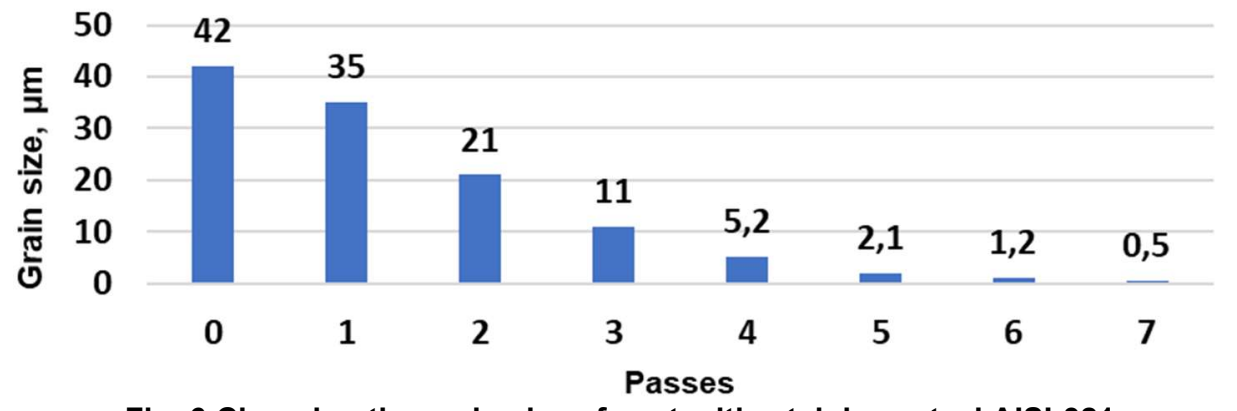

Fig. 6 Changing the grain size of austenitic stainless steel AISI-321 after radial-shear rolling by passes

According to this diagram, it can be concluded that the most intensive grinding of the structure begins after the second pass, which can be explained by the saturation of the grains of the deformable layer with dislocations due to high degrees of deformation and low rolling temperature. The initial structure of steel AISI-321 in the state of delivery has a coarse-grained structure with a grain size of about 40-50 microns. After deformation with a total stretching equal 11, an ultra-fine-grained microstructure was obtained in the peripheral part of the rod with a grain size $(300-700 \mathrm{~nm})$ comparable to the results of known studies (Tokar et al., 2018, Arbuz et al., 2018). At the same time, it should be noted that the grains of the peripheral part have an equiaxed character. The structure of 
the axial zone of the bar consists of long and narrow grains elongated in the direction of rolling and resembling the texture of rolling. After the second pass, the grain size is monotonically halved for each pass and reaches an average size of $500 \mathrm{~nm}$ at the end of rolling, i.e. after the seventh pass. The microstructure of the peripheral and axial zones after seven passes is shown in Figure 7.

a)

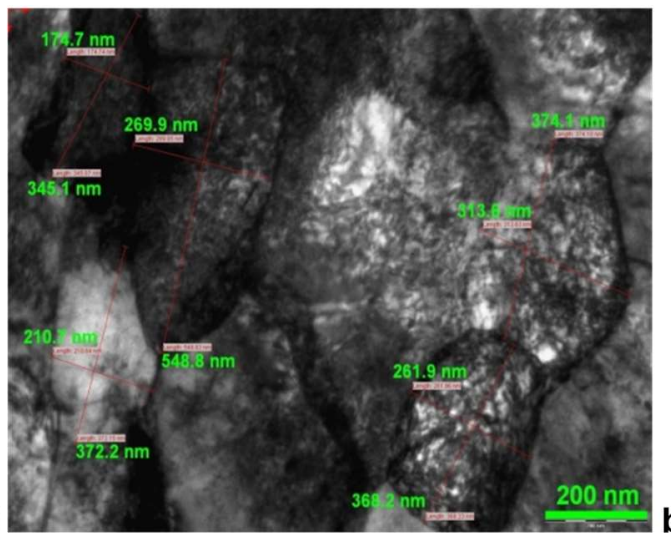

Fig. 7 Microstructure of peripheral (a) and axial

(b) zones of austenitic stainless steel AISI-321 after radial-shear rolling

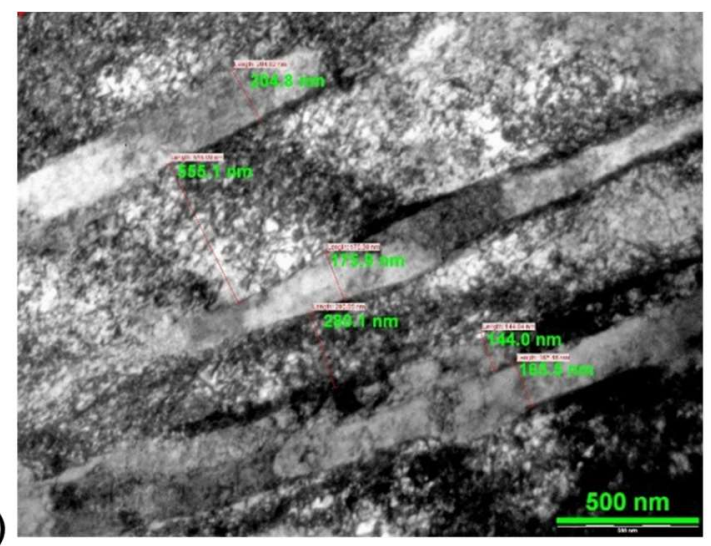

\section{CONCLUSIONS}

Improvement the quality of ferrous metal products by grinding their structure to an ultra-fine-grained state is one of the main trends in modern materials science, however, the main problem of such materials is the small final size of blanks and low technological production. The performed studies allowed to prove the possibility of obtaining an ultra-fine-grained structure in long-length blanks of austenitic stainless steel AISI-321 by radial-shear rolling, as well as to achieve a significant increase in the initial mechanical properties of this steel. Thus, in the course of experimental studies, bars with a diameter of $13 \mathrm{~mm}$ were obtained from AISI-321 steel with a grain size of $300-600 \mathrm{~nm}$, while having an inhomogeneity in the cross section of the bar. The mechanical properties and microhardness of steel AISI-321 increased more than 2 times compared to the original values.

\section{ACKNOWLEDGMENTS}

Work is performed under the state budget-funded theme № AP05131382 "Research and development of the technology for obtaining ultrafine-grained materials with improved mechanical properties and increased radiation resistance for their use as materials of the first wall of thermonuclear reactors and in nuclear power engineering" with the program "Grant financing of scientific researches on 2018-2020" (Customer - the Ministry of education and science of the Republic of Kazakhstan).

\section{REFERENCES}

Arbuz, A., Naizabekov, A., Lezhnev, S., Panin, E. (2018). Combined process "helical rolling-pressing" and its effect on the microstructure of ferrous and non-ferrous materials, Metall. Res. Technol., 115, 213. 
ASM Metals Hand Book. (2002). Fatigue and Fracture. ASM International.

Bhadeshia, H. K. D. H. (2014). Physical Metallurgy. Materials Science And Technology, 30(9), pp. 995-997.

Bloom, E.E. (1998).The challenge of developing structural materials for fusion power system.Journal of Nuclear Materials, 258-263, pp. 7-17.

Dobatkin, S., Galkin, S., Estrin, Y., Serebryany, V., Diez, M., Martynenko, N., Lukyanova, E. and Perezhogin, V. (2019).Grain refinement, texture, and mechanical properties of a magnesium alloy after radial-shear rolling. Journal of Alloys and Compounds, 774, pp. 969-979.

Ge, X., Li, J., Wang, H, Zhang, C., Liu, Y. and Luo, J. (2019). Macroscale super lubricity under extreme pressure enabled by the combination of graphene-oxide nanosheets with ionic liquid. Carbon, 151, pp. 76-83.

Ghazani, M.S. and Eghbali, B. (2018).Characterization of the hot deformation microstructure of AISI 321 austenitic stainless steel. Materials Science and Engineering A - Structural Materials Properties Microstructure and Processing, 730, pp. 380-390.

Kalinin, G., Barabash, V., Cardella, A., Dietz, J., loki, K., Matera, R., Santoro, R.T. and Tivey, R. (2000). The ITER Home Teams.Assessment and selection of materials for ITER in-vessel Components.Journal of Nuclear Materials, 283-287, pp.10-19.

Koch, C.C., Ovid'ko, I.A., Seal, S. and Veprek, S. (2007) Structural nanocrystalline materials: Fundamentals and applications. Cambridge: Cambridge University Press.

Lenard, J.G. (2013). Primer on Flat Rolling. Amsterdam: Elsevier.

Lenard, J.G., Pietrzyk, M. and Cser L. (2005). Mathematical and Physical Simulation of the Properties of Hot Rolled Products. Amsterdam: Elsevier.

Lezhnev, S.N., Naizabekov, A.B., Panin, E.A. and ArbuzA.S. (2018). Computer simulation of microstructure evolution in radial-shear rolling using SIMUFACT FORMING software and MATILDA material database.XIX International scientific conference «New technologies and achievements in metallurgy, material engineering, production engineering and physics», Częstochowa, p. 31-34.

Maksimkin, O. P., Gusev, M.N., Tsai, K.V., Yarovchuk, A.V., Rybalchenko, O.V., Enikeev, N.A., Valiev, R.Z. and Dobatkin, S.V. (2015). Effect of neutron irradiation on the microstructure and the mechanical and corrosion properties of the ultrafinegrained stainless $\mathrm{Cr}-\mathrm{Ni}$ steel. Physics of metals and metallography, 116(12), pp. 1270-1278.

Mansur, L.K., Rowcliffe, A.F., Nanstad, R.K., Zinkle, S.J., Corwin, W.R. and Stoller R.E. (2004). Materials needs for fusion, Generation IV fission reactors and spallation neutron sources - similarities and differences. Journal of Nuclear Materials, 329333, pp. 166-172.

Murty, K.L. and Charitl. (2008). Structural materials for Gen-IV nuclear reactors: Challenges and opportunities. Journal of Nuclear Materials, 383, pp. 189-195.

Nayzabekov, A., Lezhnev, S., Panin, E., Arbuz, A. and Koinov, T. (2018). Computer modelling of radial-shear rolling of austenitic stainless steel AISI-321. Machines, Technologies, Materials, 12, pp. 497-500.

Rajputa, S.K., Chaudhari, G.P. and Nath, S.K. (2016). Characterization of hot deformation behavior of a low carbon steel using processing maps, constitutive equations and Zener-Hollomon parameter. Journal of Materials Processing Technology, 237, pp. 113-125.

Rybalchenko, O.V., Tokar, A.A., Terentyev, V.F., Prosvirnin, D.V., Raab, G.I. and Dobatkin, S.V. (2016). Effect of equal-channel angular pressing in the temperature range $200-400^{\circ} \mathrm{C}$ on the performance properties of steel $08 \mathrm{H} 18 \mathrm{~N} 10 \mathrm{~T}$. VI Russian conference on nanomaterials with elements of scientific school for youth, pp. 321322.

Sheremetyev, V., Kudryashova, A., Cheverikin, V., Korotitskiy, A., Galkin, S., Prokoshkin, S. and Brailovski, V. (2019). Hot radial shear rolling and rotary forging of metastable beta Ti-18Zr-14Nb (at. \%) alloy for bone implants: Microstructure, 
texture and functional properties. Journal of Alloys and Compounds, 800, pp. 320326.

Tokar, A.A., Rybalchenko, O.V., Belyakov, A.N., Prosvirnin, D.V., Taranchuk, V.I., Terent'ev, V.F., Raab, G.I. and Dobatkin, S.V. (2018). Microstructure and fatigue properties of austenitic corrosion-resistant steel 08H18N10T after equal-channel angular pressing and subsequent heating. Proceedings of IX-th Eurasian scientificpractical conference. p. 97.

Valiev, R.Z., Islamgaliev, R.K. and Alexandrov, I.V. (2000).Bulk nanostructured materials from severe plastic deformation. Progress in Materials Science, 45(2), pp. 103-189.

Yvon, P. and Carr F. (2009). Structural materials challenges for advanced reactor systems. Journal of Nuclear Materials, 385, pp. 217-222.

Zinkle, S.J. and Was, G.S. (2013). Materials challenges in nuclear energy. ActaMaterialia, 61, pp. 735-758.

Zinkle, S.J. and Busby, J.T. (2009).Structural materials for fission \& fusion energy. Materials Today, 12, pp. 12-19.

\begin{abstract}
.
Nuclear power is associated with great environmental risks. In many cases, the problem of accidents of nuclear power plants is related to the use of materials that do not fully meet the following requirements: high corrosion resistance; high temperature resistance; creep resistance; fracture toughness; stability of structure and properties under irradiation. Therefore, studies aimed at finding materials that can withstand long-term loads at high temperatures, aggressive environment and gradual structural degradation under the influence of radiation are relevant. One of the structural materials, which has high resistance to radiation, is austenitic stainless steel. And one of the ways to increase the radiation resistance of parts made of this steel grade is to grind its microstructure to ultra-fine-grained state. Such structures provide a combination of a high level of strength characteristics with high plasticity, which distinguishes such materials from their coarse-grained counterparts. Also, numerous grain boundaries serve as runoff surfaces for radiation defects, preserving the structure, which causes their increased radiation resistance. From all methods for producing sub-ultra-finegrained materials the most promising is the severe plastic deformation (SPD), which can be implemented in the metal in various ways, including radial-shear rolling. This paper presents the results of studies of the process of radial-shear rolling on the mill SVP-08 and its effect on the microstructure and properties of austenitic stainless steel. During the study, bars with a diameter of $13 \mathrm{~mm}$ from AISI-321 steel with a grain size of 300-600 nm were obtained, while the mechanical properties increased more than 2 times compared to the initial values.
\end{abstract}

Keywords: radial-shear rolling, austenitic stainless steel, severe plastic deformation, ultrafine-grained materials 